\title{
The Effect of Mentalization-Based Therapy on the Amount of Health Promoting Behaviors in People with Coronary Heart Disease
}

\section{Issa Mohammadi ${ }^{1}$, Biyuk Tajeri ${ }^{* *}$, Sheida Sodager ${ }^{1}$, Maryam Bahrami Heidaji², Akbar Atadokht ${ }^{3}$}

${ }^{1}$ Department of Health Psychology, Karaj Branch, Islamic Azad University, Karaj, Iran

${ }^{2}$ Department of Psychology, Karaj Branch, Islamic Azad University, Karaj, Iran

${ }^{3}$ Department of Psychology, Faculty of Educational Sciences and Psychology, Mohaghegh Ardabili University, Ardabil, Iran

\section{A BSTRACT}

Introduction: Health promoting behaviors are vital for anyone, particularly for those with coronary heart disease. Accordingly, the present study has been aimed to survey the effectiveness of mentalization-based therapy on health promoting behaviors in patients with coronary heart disease. Materials and Methods: the study is an experimental one with pre-test and post-test design. The sample included 40 men with cardiac disease. They were chosen by purposive sampling and were coincidentally divided into the experimental and control groups. The mentalization therapy was run to the experimental group. The Walker and Hill (1997) health promotion questionnaire were used for data gathering. Results: Mentalization-based therapy exerted a significant effect on the enhancement of health promoting behaviors in the experimental group compared with controls. Conclusion: Mentalization-based therapy is an appropriate strategy to increase health promoting behaviors in patients with coronary heart disease and it can be used as an effective intervention method.

*Corresponding Author: Biyuk Tajeri

E-mail: btajeri@yahoo.com 


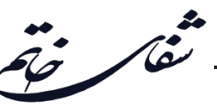

اثربخشى درمان مبتنى بر ذهنىسازى بر ميزان رفتارهاى ارتقاءدهندهُ سلامت در افراد مبتلا به بيمارى

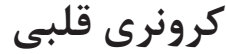

عيسى محمدى'، بيوك تاجرى"'، شيدا سوداكر '، مريم بهر امى هيدجى '، اكبر عطادخت"

'حروه روانشناسى سلامت، واحد كرج، دانشكاه آزاد اسلامى، كرج، ايران

rكروه روانشناسى، واحد كرج، دانشكاه آزاد اسلامى، كرج، ايران

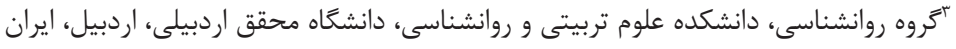

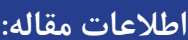

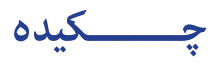

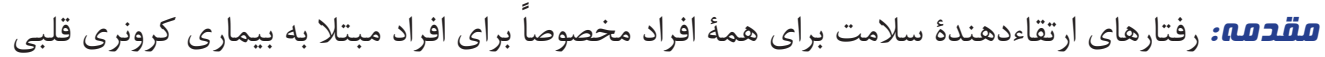

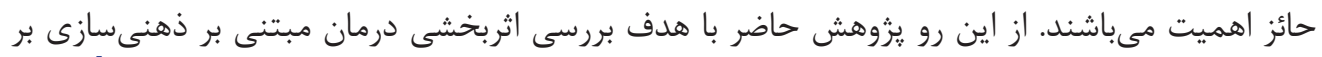

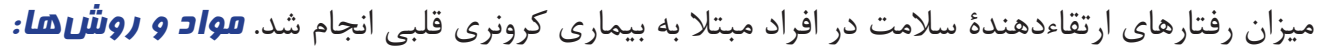

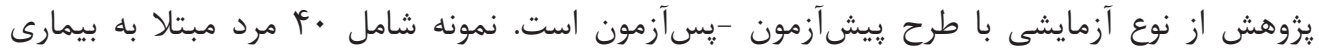

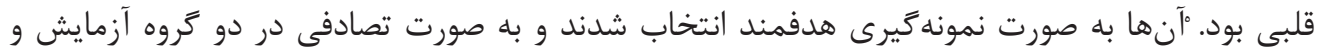

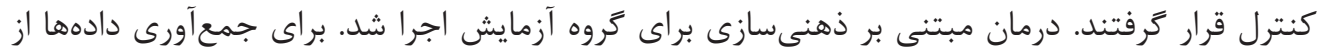

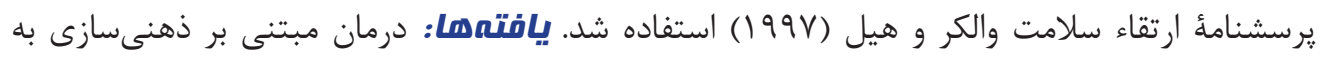

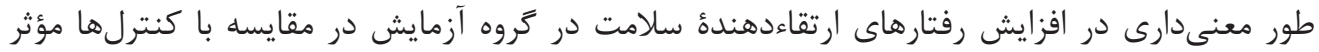

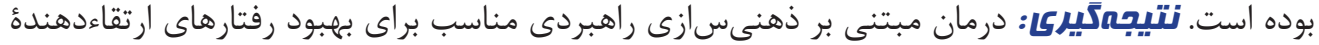

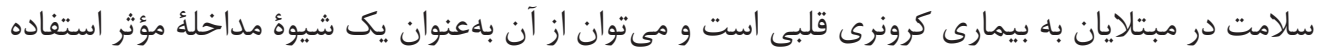

\footnotetext{
: ت كليد وازهها: (1)

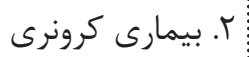

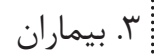




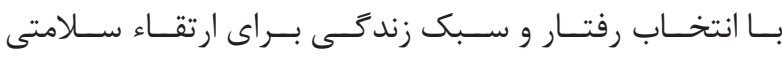

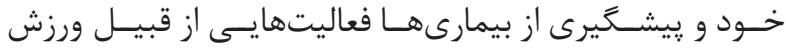

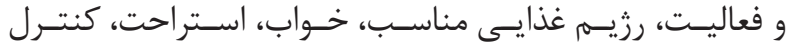

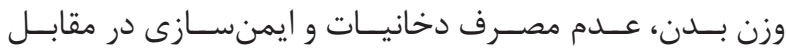

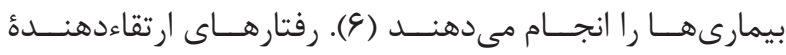

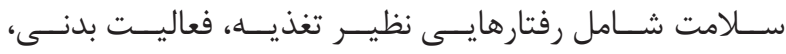

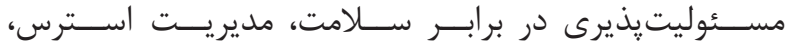

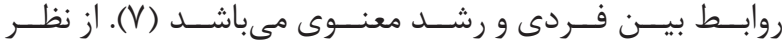

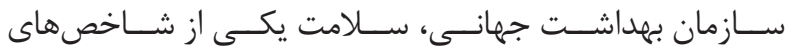

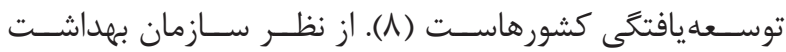

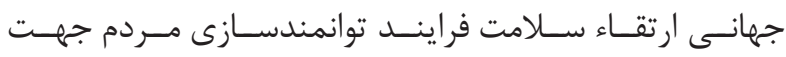

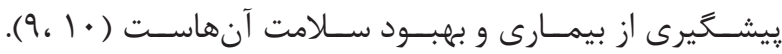

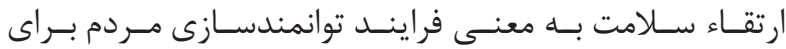

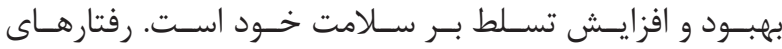

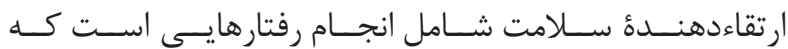

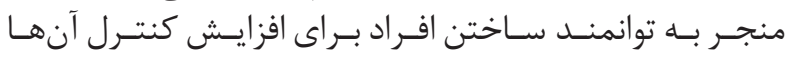

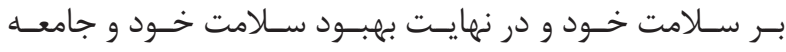

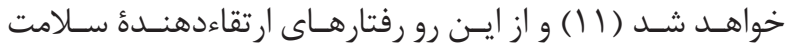

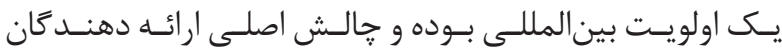

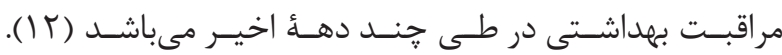

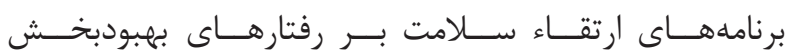

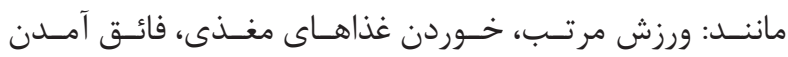

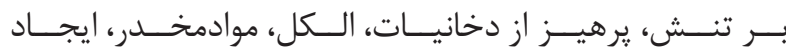

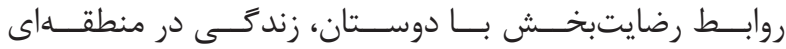

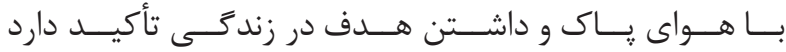

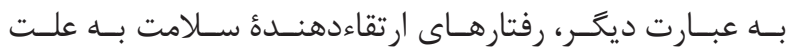

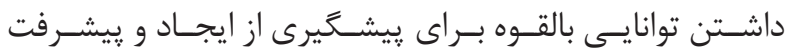

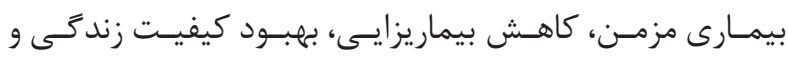

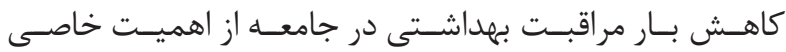

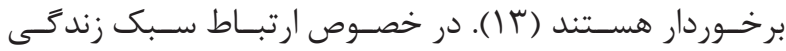

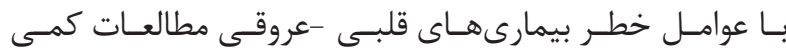

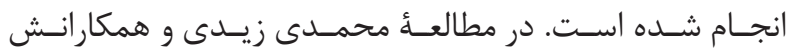

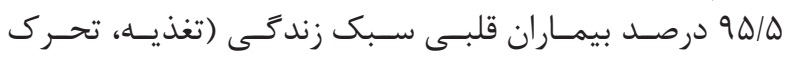

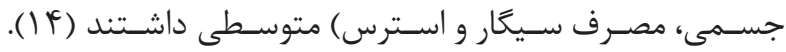

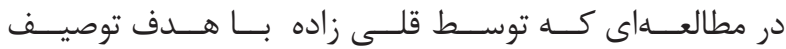

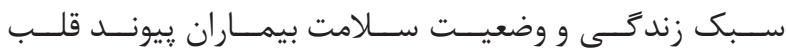

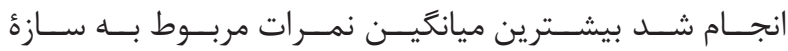

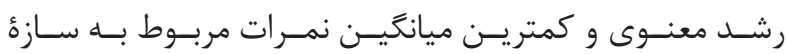

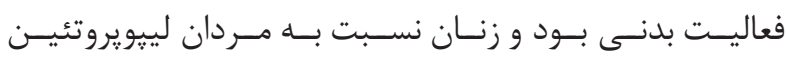

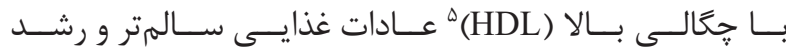

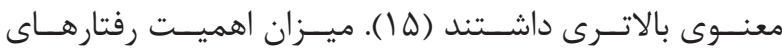

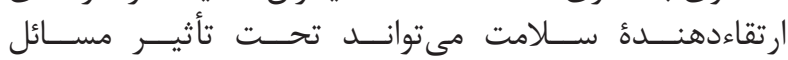

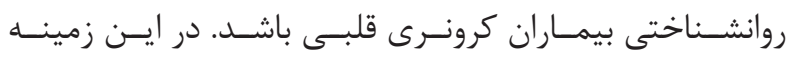

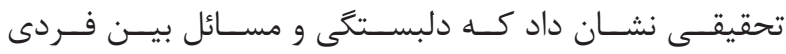

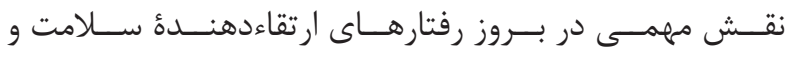

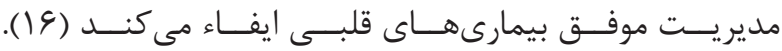

${ }^{1}$ Cardiac coronary disease

${ }^{2}$ Chest pain

${ }^{3}$ Angina pectoris

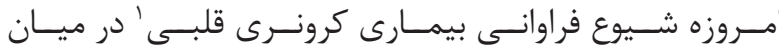

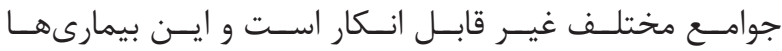

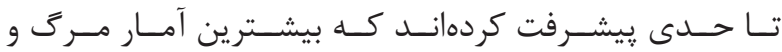

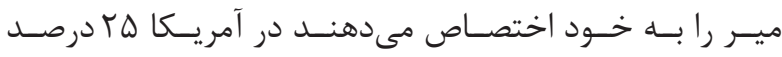

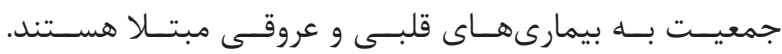

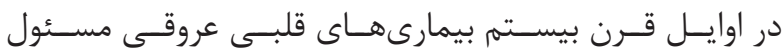

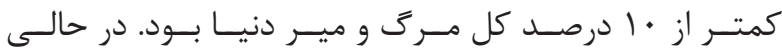

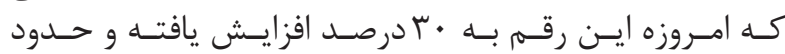

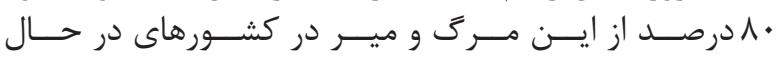

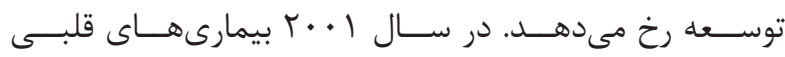

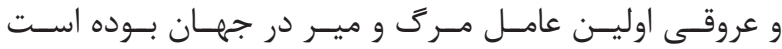

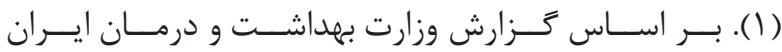

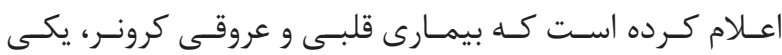

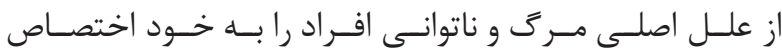

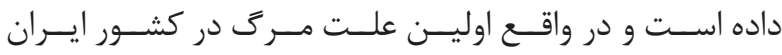

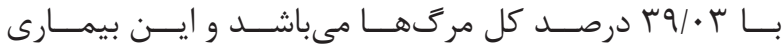

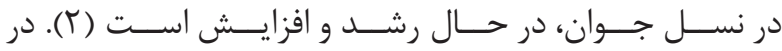

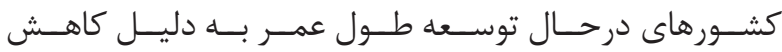

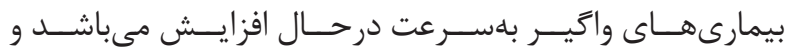

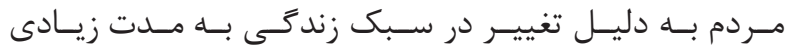

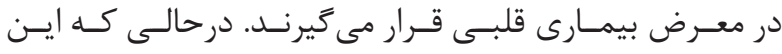

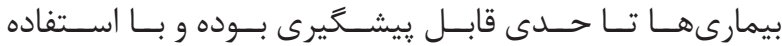

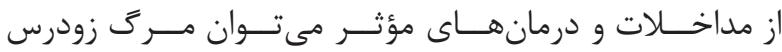

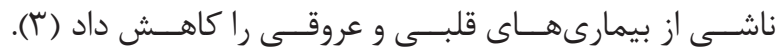

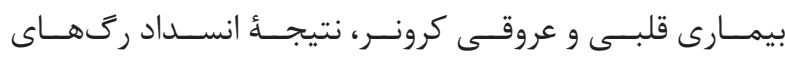

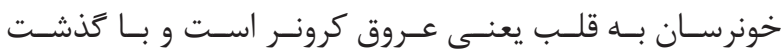

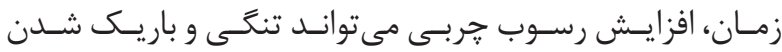

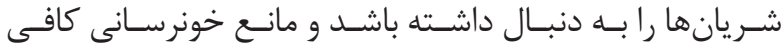

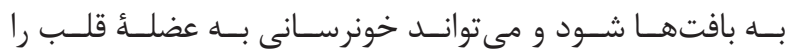

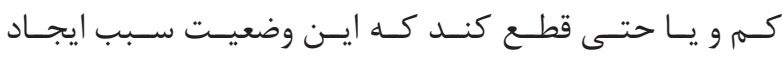

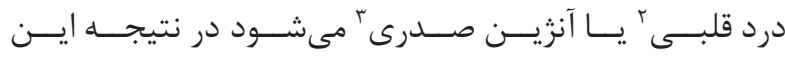

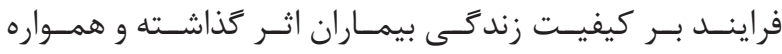

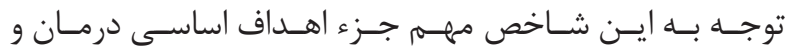

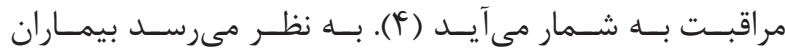

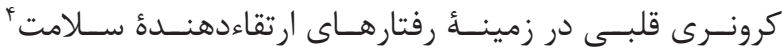

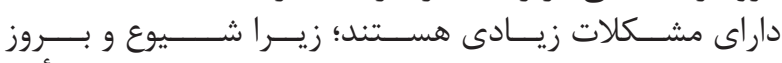

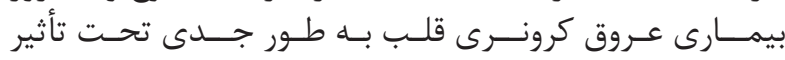

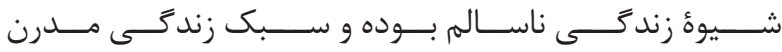

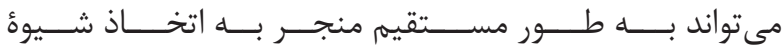

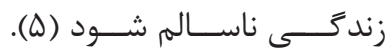

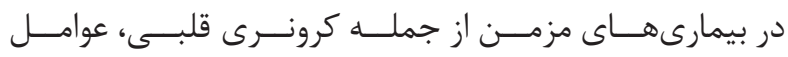

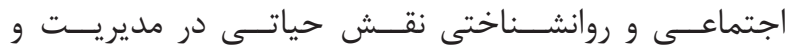

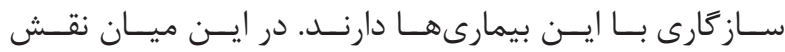

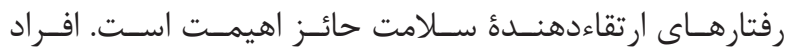

${ }^{4}$ Health promoting behaviors

${ }^{5}$ High density lipoprotein 


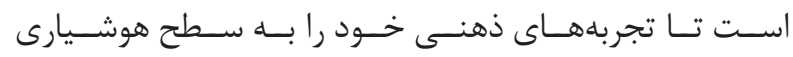

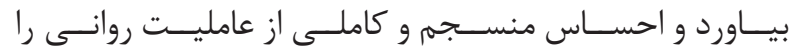

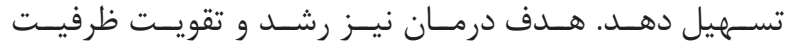

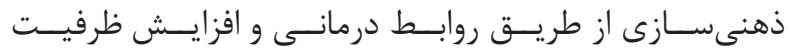

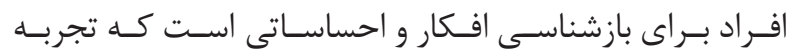

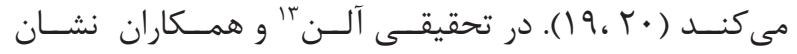

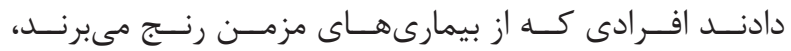

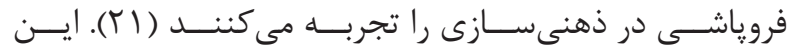

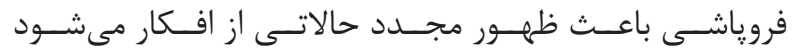

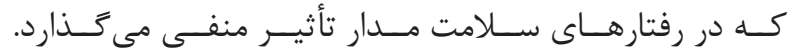

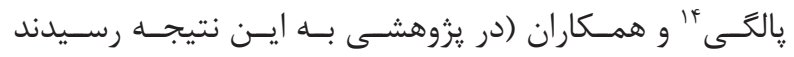

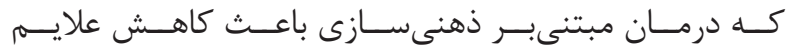

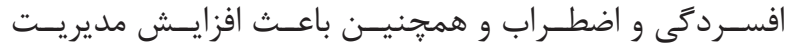

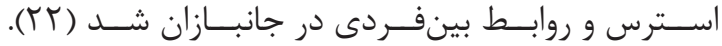

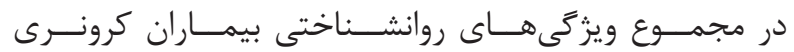

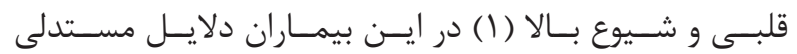

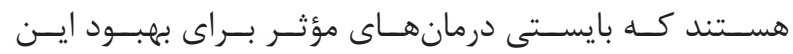

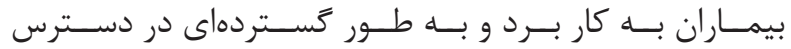

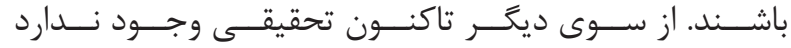

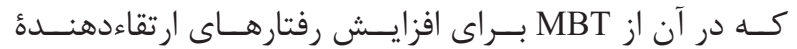

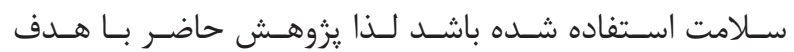

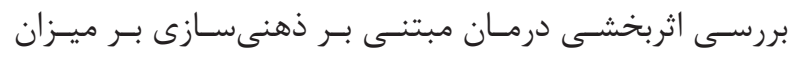

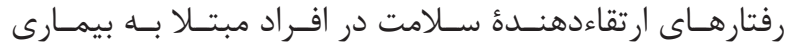

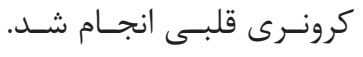

مواد و روشها

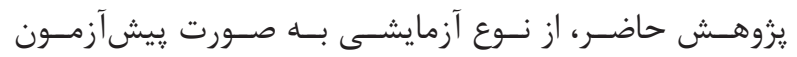

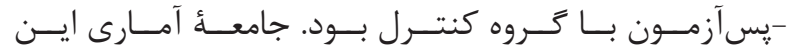

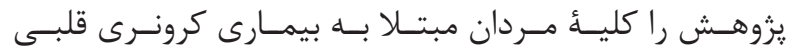

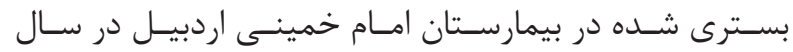

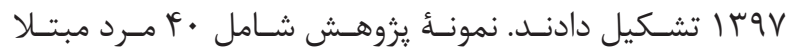

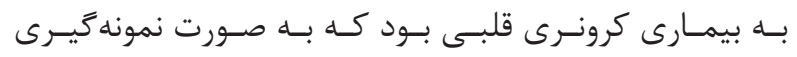

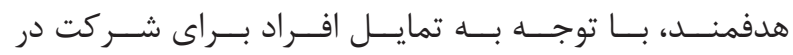

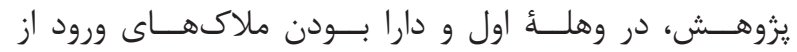

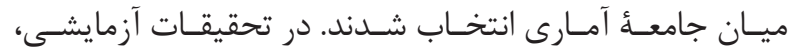

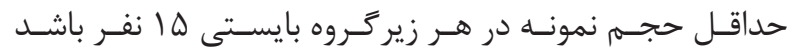

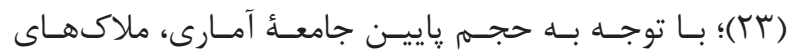

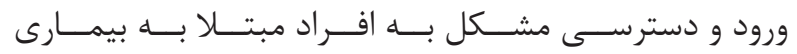

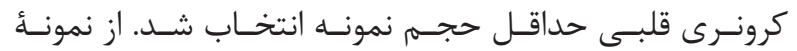

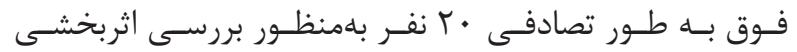

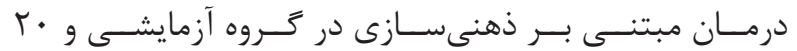

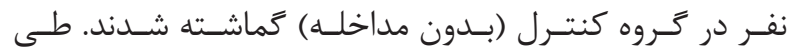

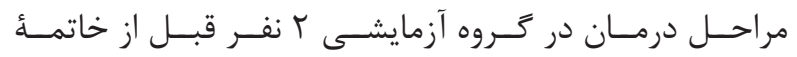

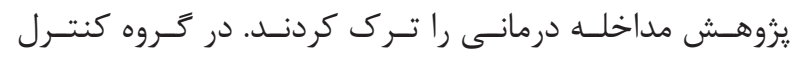

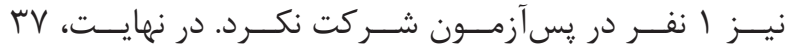

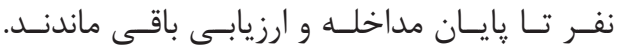

\footnotetext{
${ }^{6}$ Mentalization based therapy

7 Bateman, Fonagy

${ }^{8}$ Nonmentalizing modes

${ }^{9}$ Psychic equivalence mode

${ }^{10}$ Teleological mode
}

همجنيـن دلبسـتخى نايمـن و تجربيـات ذهنــى و هيجانـات

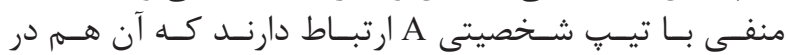

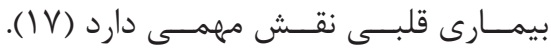

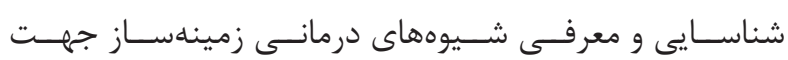

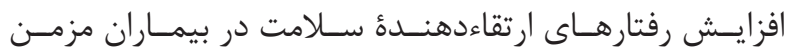

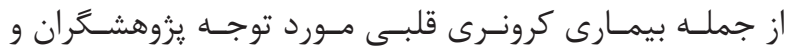

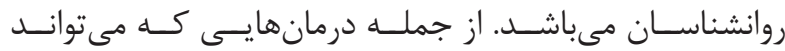

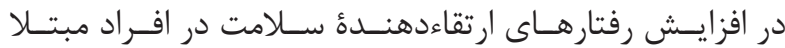

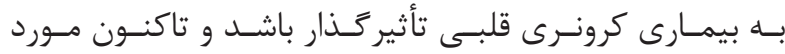

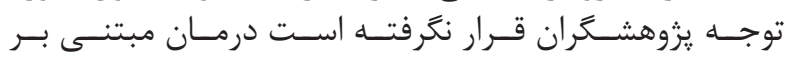

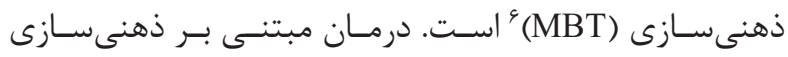

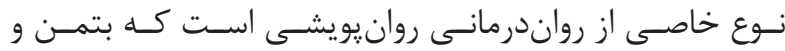

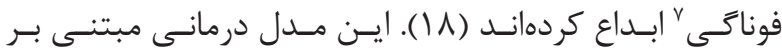

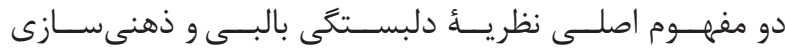

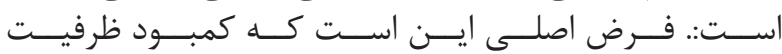

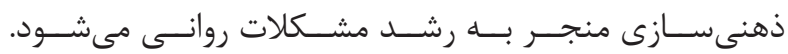

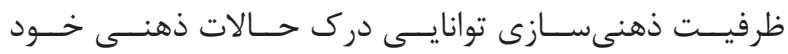

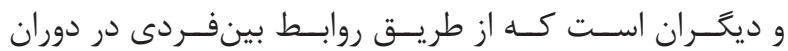

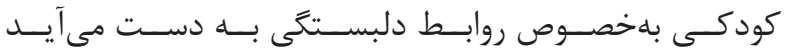

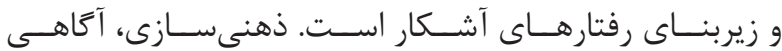

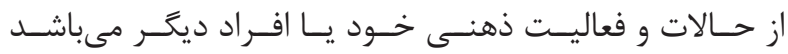

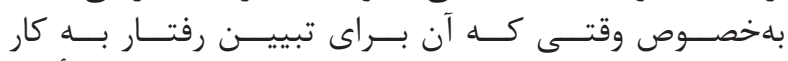

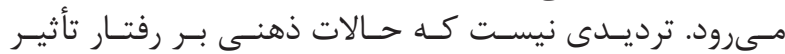

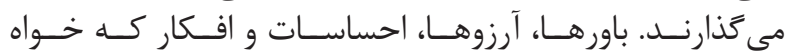

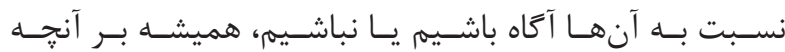

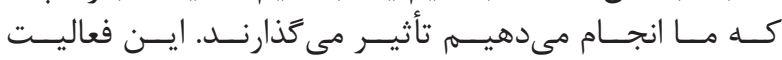

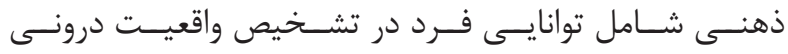

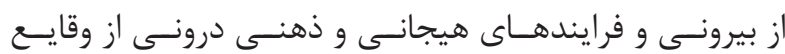

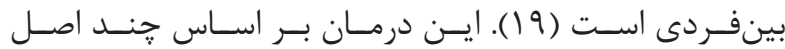

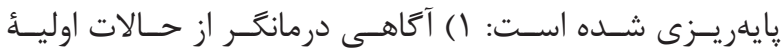

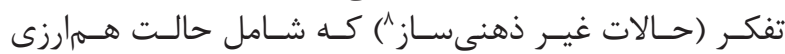

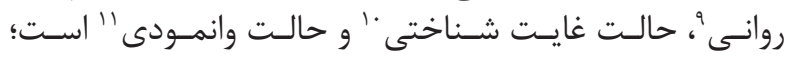

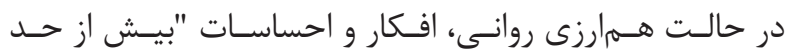

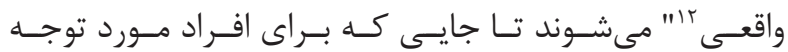

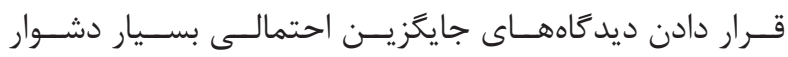

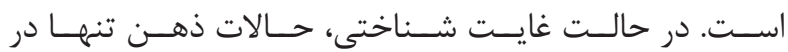

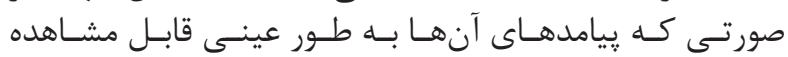

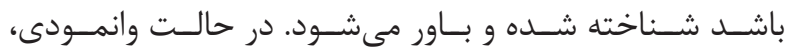

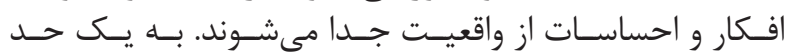

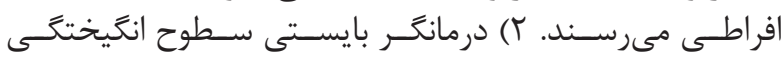

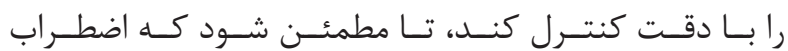

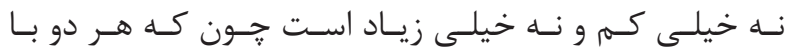

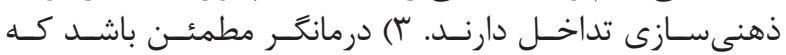

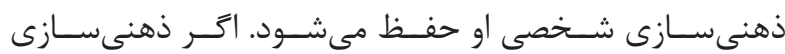

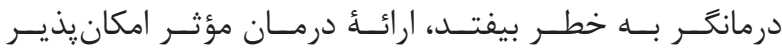

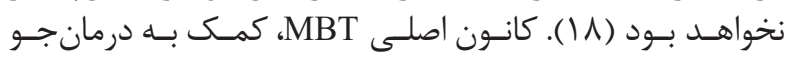

${ }^{11}$ Pretend mode

${ }^{12}$ Too real

${ }^{13}$ Allen

${ }^{14}$ Palgi 


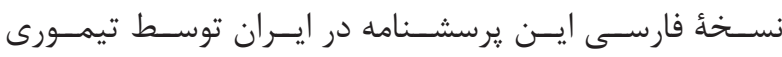

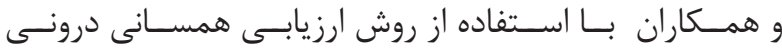

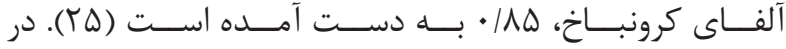

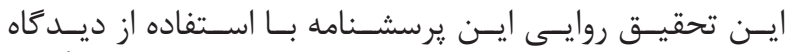

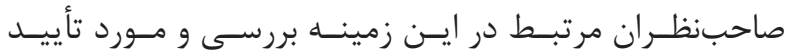

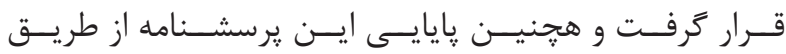

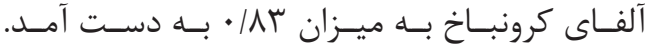

$$
\text { درمان مبتنى بر ذهنىسازى }
$$

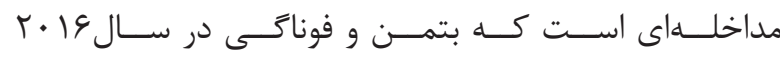

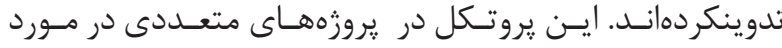

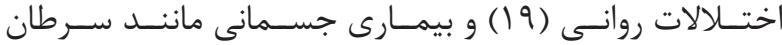

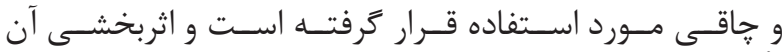

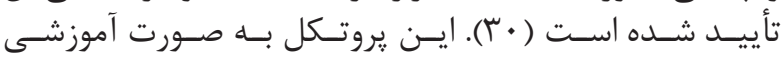

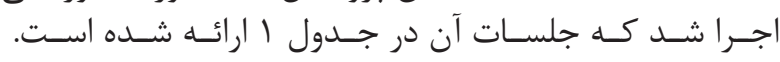

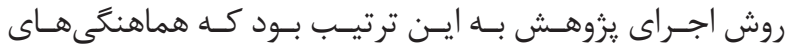

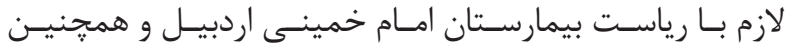

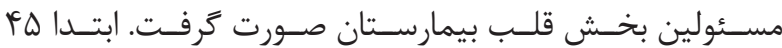

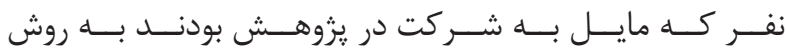

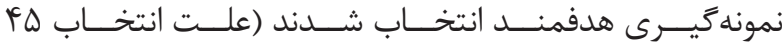

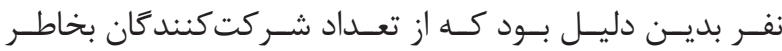

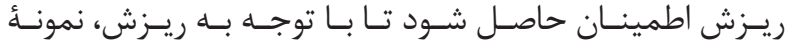

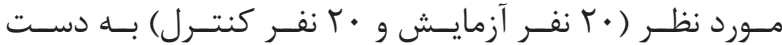

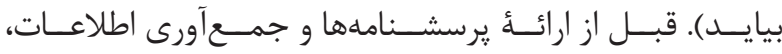

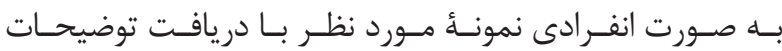

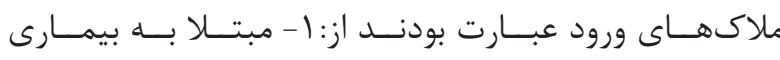

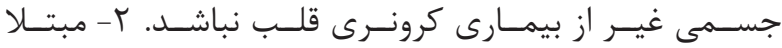

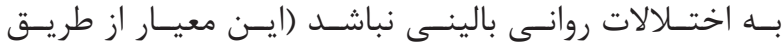

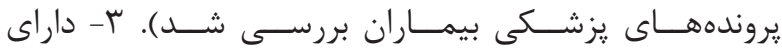

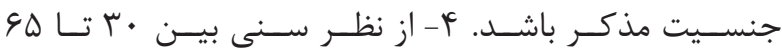

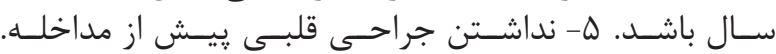

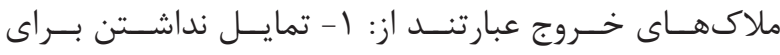

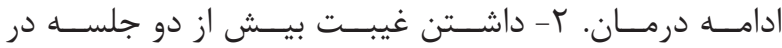

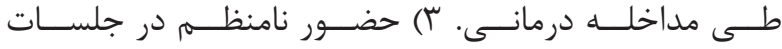

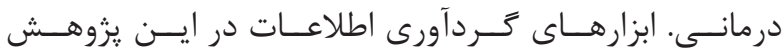

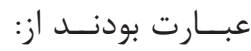
يرسشنامهُ ار تقاء سالامت

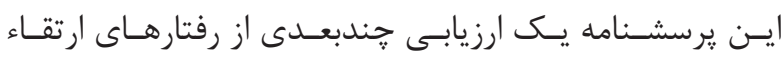

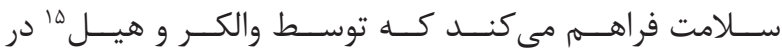

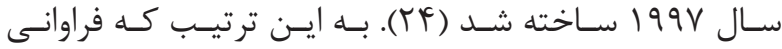

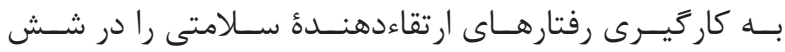

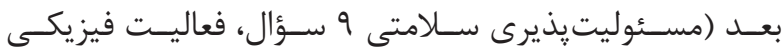

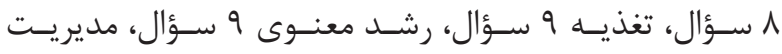

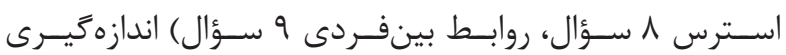

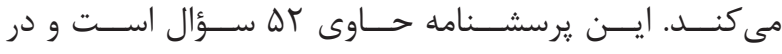

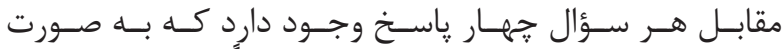

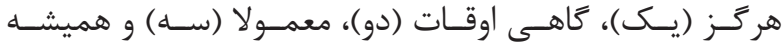

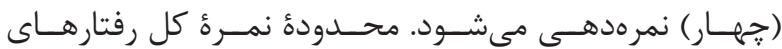

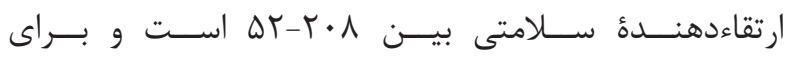

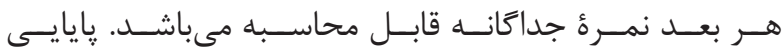

جدول ا- محتواى جلسات MBT به تفكيك جلسات بركرفته از يروتكل درمانى بتمن و فوناگى.

\begin{tabular}{|c|c|}
\hline مجتوى جلسات & جلسات \\
\hline فهذثىسازى حيست؟ & اول \\
\hline 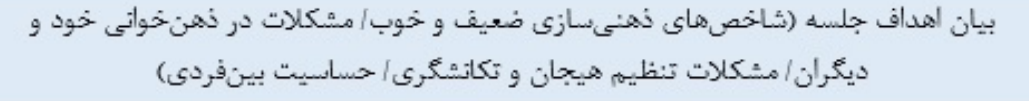 & دوم \\
\hline حرا ما هيجان داريم و هيجاتات الصلى كدامند؟ & سوم \\
\hline ذهنى سازى هيجاتات، تفسير علامتهاى هيجاتى دروتى در خودمان و حالات هيجاتى در ديكران & جهار مجه \\
\hline دالبستكى و راهبردهاى دلبستكى در بزركسالى & ينجمه \\
\hline دلبستةكى و ذهنى & ششم شم \\
\hline بيمارى كروثرى قليى هيـست؟ & هفتم هفم \\
\hline درمان و آموزث مبيتشى بر ذهنـىسازى & هشتبم \\
\hline 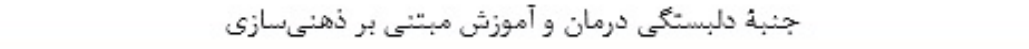 & ثهष \\
\hline ارائة آموزش در مورد اضطراب و تردى & Sم \\
\hline ارائه رويكرد آموزثى در مورد الفسردكى & يازٔدهم \\
\hline خلاصه و تتيجهكيرى & دواز دهم \\
\hline
\end{tabular}

${ }^{15}$ Walker and Hill 


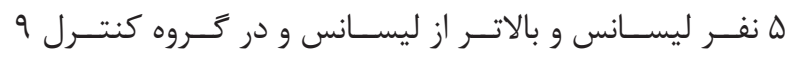

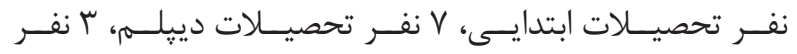

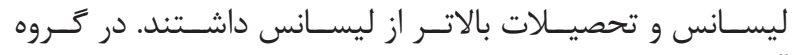

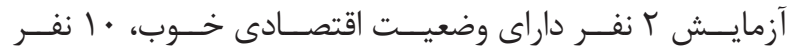

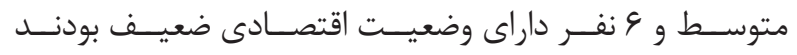

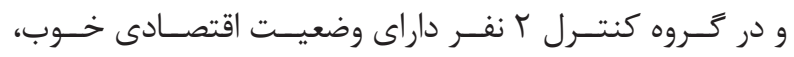

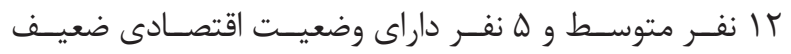

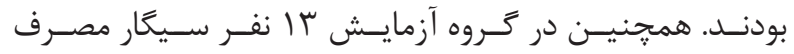

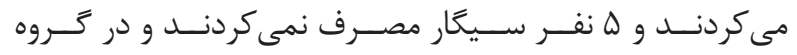

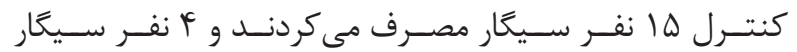

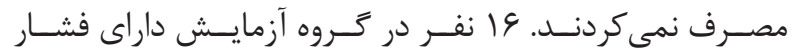

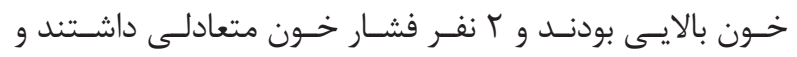

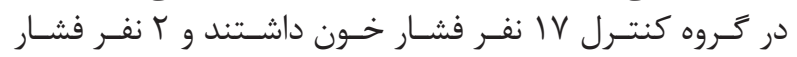

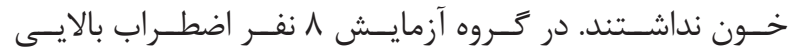

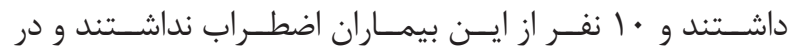

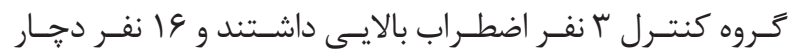

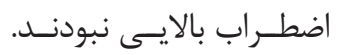

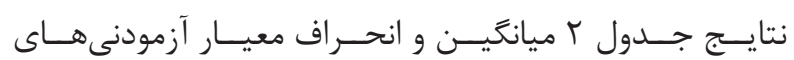

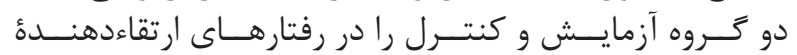

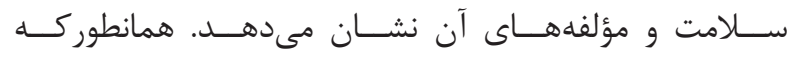

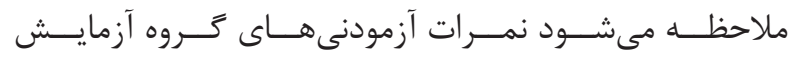

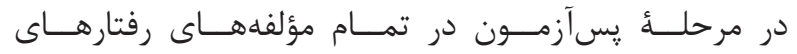

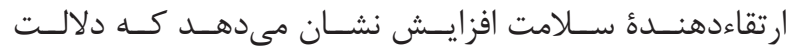

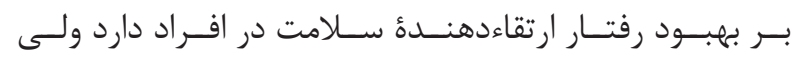

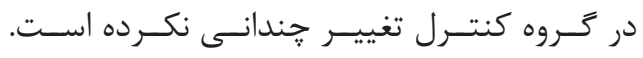

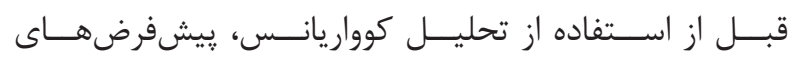

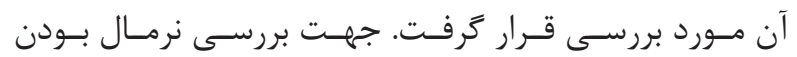

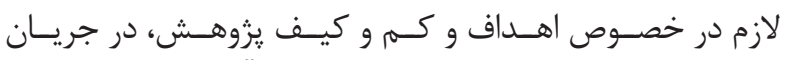

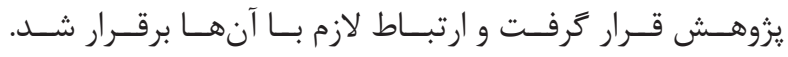

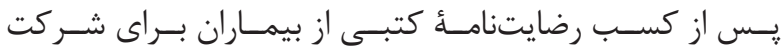

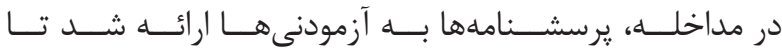

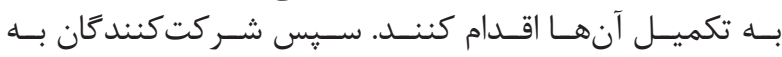

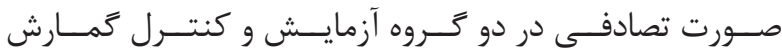

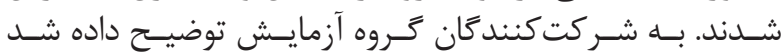

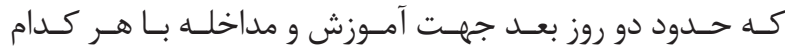

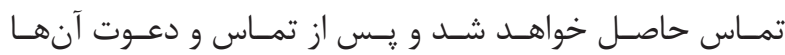

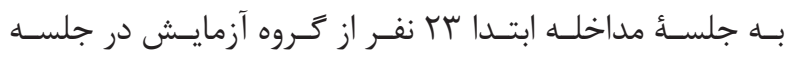

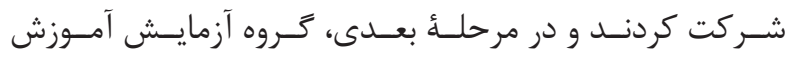

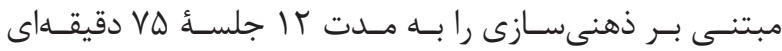

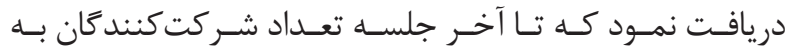

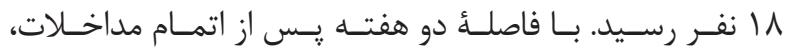

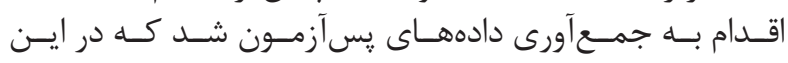

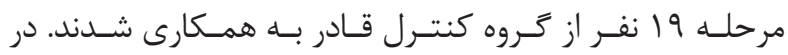

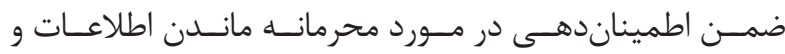

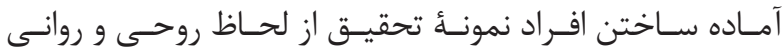

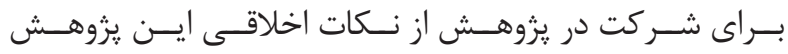

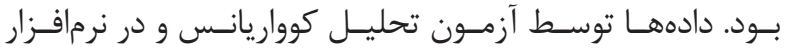

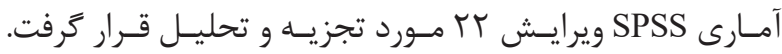

بافتهها

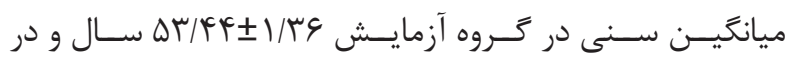

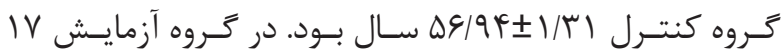

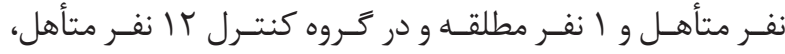

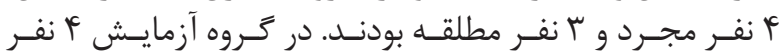

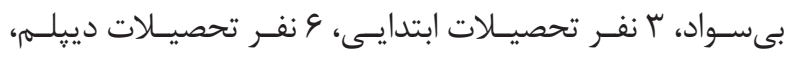

جدول r- ميانگَين و انحراف معيار پِيشآزمون، پِآزمون رفتارهاى ارتقاء سلامت و مؤلفههاى آن در گروههاى آزمايش و كنترل.

\begin{tabular}{|c|c|c|c|c|}
\hline يس آزمون & يُشئزآمون & \multirow{2}{*}{ تعداد } & \multirow{2}{*}{ تيروه } & \multirow{2}{*}{ متغير } \\
\hline انتراف معيارئيائتين & أتحراف معيارئمياثُّين & & & \\
\hline$r \cdot / V V \pm r / \cdot r$ & $r / / V T \pm r / \Delta \Lambda$ & 11 & آزمايش & \multirow{2}{*}{ تخذيه } \\
\hline$r r / \wedge 9 \pm r / l \cdot$ & $r|/ r| r \pm / 1 \wedge$ & 19 & كنترل & \\
\hline$r r / r V \pm r / V \Delta$ & $\mid f / + \pm t / 9 r$ & 11 & آزمايش & \multirow{2}{*}{ ورزش } \\
\hline$r+1+ \pm \pm 1 / r q$ & $10 / 9+ \pm \Delta / \cdot V$ & 19 & كنترل & \\
\hline$|9 / 9| \pm r|\Lambda|$ & $14 / 99 \pm 1 / 97$ & 11 & آزمايش & \multirow{2}{*}{ مسئوليتهِيرى } \\
\hline $\mid \Delta / F V \pm 1 / \Delta F$ & $\mid F / G \Lambda \pm r / \Delta \Lambda$ & 19 & كنترل & \\
\hline $19 / r r \mid \pm / 91$ & $1+199 \pm 1 / 9$ & 11 & آزمايش & \multirow{2}{*}{ مديريت استرس } \\
\hline $\mid \Delta / 10 \pm 1 / \% \wedge$ & $1+1+ \pm r / 4 *$ & 19 & كنترل & \\
\hline$r r / r \Delta \pm r / r+$ & $11 / 19 \pm r / \Delta 9$ & 11 & آزمايش & \multirow{2}{*}{ حمايت بينفردى } \\
\hline$r+/ V r \pm r / 9 q$ & $|\Delta / F r \pm r / \Lambda|$ & 19 & كنترل & \\
\hline$r r / \wedge r \pm 1 / 9 f$ & $\| / F F \pm r / 1 F$ & 11 & 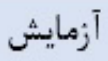 & \multirow{2}{*}{ خودشكوفايى } \\
\hline $1 V / 19 \pm r / r 9$ & $1 \cdot / r G \pm r / V r$ & 19 & كنتـرل & \\
\hline$|\Delta r / 19 \pm 9|+r$ & $Q / / 9 \mid \pm \Delta / 9$. & 11 & آزمايش & \multirow{2}{*}{ 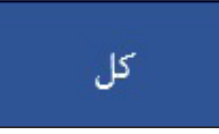 } \\
\hline $\mid r / / 1 \Delta \pm V / \& q$ & $\Lambda V / V T \pm F / r \Lambda$ & 19 & كنتـرل & \\
\hline
\end{tabular}




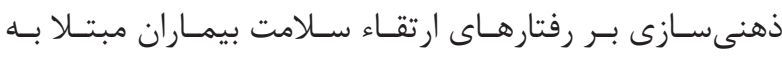

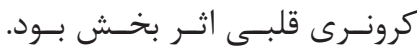

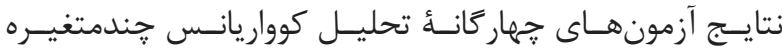

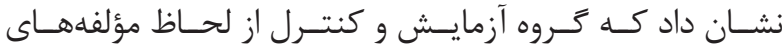

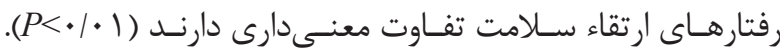

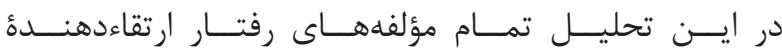

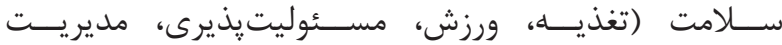

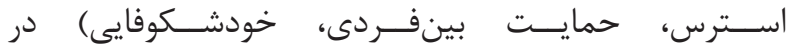

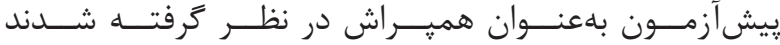

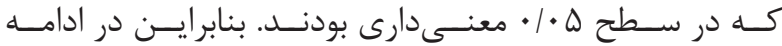

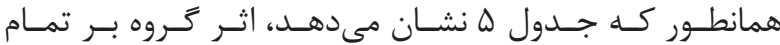

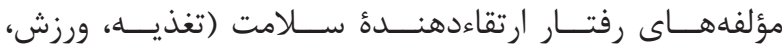

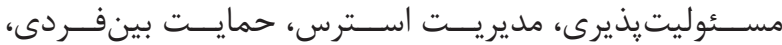

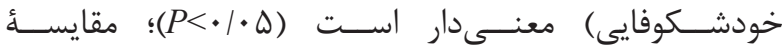

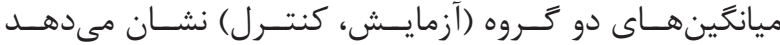

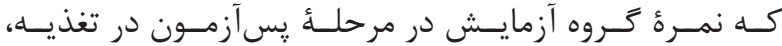

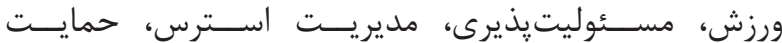

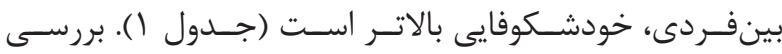

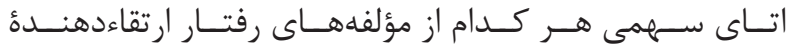

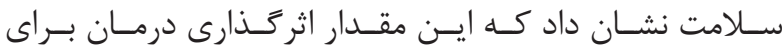

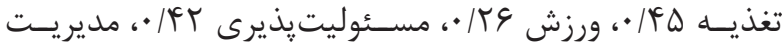

توزيــع دادههــا از آزمــون كولموخــروف -اسـميرنوف اســفـاده

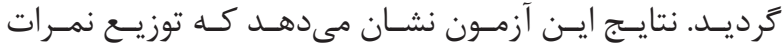

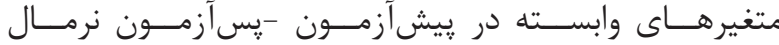

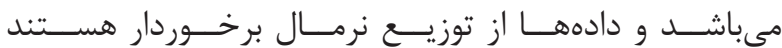

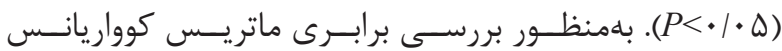

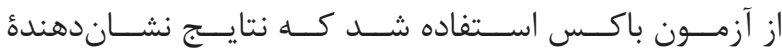

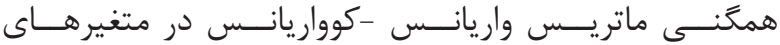

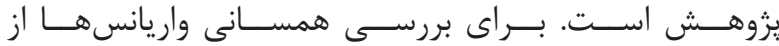

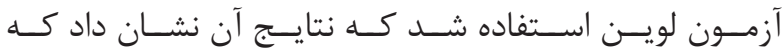

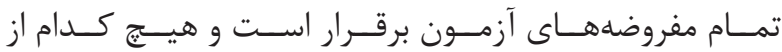

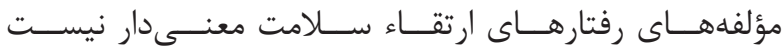

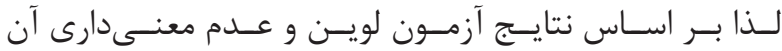

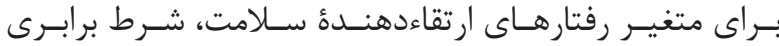

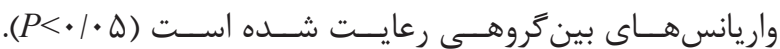

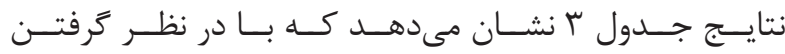

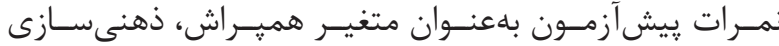

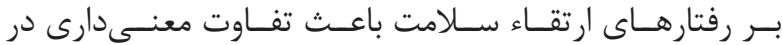

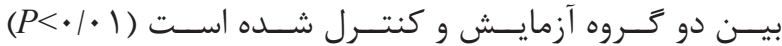

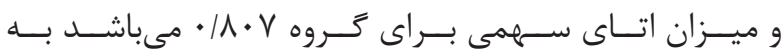

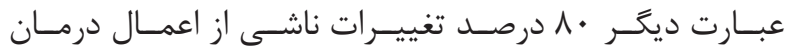

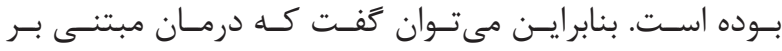

جدول بـ نتايج تحليل كوواريانس تك متغيره براى مقايسة رفتار ارتقاء سلامت در دو كروه آزمايش و كنترل.

\begin{tabular}{|c|c|c|c|c|c|c|}
\hline اتا & سطح معنى دارى & F & ميانكين مجذورات & درجهُ آزادى & مجموع مجذورات & منبع تخييرات \\
\hline$\cdot|T V|$ & $\cdot 1 \cdot \uparrow \wedge$ & ५/৭६. & ITNFqT & 1 & $\mid r N / F q T$ & ييشآزمون \\
\hline$\cdot \mid \Lambda \cdot V$ & $\cdot 1 \cdots$ & $|\& Y / \Delta \Lambda|$ & $9999 / 991$ & 1 & $9499 / 991$ & كروه \\
\hline - & - & - & $\varphi \varphi / V \Lambda$. & ry & $1 \Delta q \cdot / \Delta r F$ & خطا \\
\hline
\end{tabular}

جدول F- نتايج تحليل كوواريانس تفاوت كلى گروهها در بس آزمون نمرات مؤلفهاى ارتقاء سلامت.

\begin{tabular}{|c|c|c|c|c|c|c|}
\hline اتا & سطح معنى دارى & درجة آزادى خطا & درجة آزادى فرضيه & $\mathbf{F}$ & مقدار & نام آزمون \\
\hline$\cdot / \mathrm{\wedge}$. & $\cdot / \cdots$ & rF & $\varepsilon$ & $1 f / 111$ & $\cdot / \mathrm{\wedge}$. & اثر ييلايى \\
\hline$\cdot / \mathrm{r}$. & $\cdot 1 \cdots$ & rf & \& & $\mid f / 1 \wedge \Lambda$ & $\cdot / T r \cdot$ & لامبدا ويلكز \\
\hline$\cdot / \mathrm{\wedge}$. & $\cdot / \cdots$ & rF & 4 & $1 f / 111$ & $r / \Delta F V$ & اثر هتلينت \\
\hline - /VA. & $\cdot / \cdots$ & rf & $\varepsilon$ & $\mid f / 111$ & $r / \Delta F V$ & بزرتىترين ريشهروى \\
\hline
\end{tabular}

جدول ه- نتايج تحليل كوواريانس براى بررسى اثربخشى درمان مبتنى بر ذهنىسازى بر مؤلفههاى رفتار ارتقاءدهندة سلامت.

\begin{tabular}{|c|c|c|c|c|c|c|c|}
\hline اتا & معنى سطح & F & ميانكَين مجنورات & درجة آزادى & مجموع مجذورات & منبع تغييرات & متغير \\
\hline$\cdot / F D$. & $\cdot / \cdots$ & Tr/VTS & & 1 & גזי/rtr & تغذيه & \\
\hline$\cdot / T \Delta \Delta$ & $\cdot / * r$ & १/१५१ & $V V / \Lambda \cdot V$ & 1 & $V V / \Lambda \cdot V$ & ورزش & \\
\hline . AYq & $\cdot / \cdots$ & TI/AIT & $9 \Delta / \cdot \varnothing ८$ & 1 & $9 \Delta / \cdot 99$ & مسئوليتيذيرى & \\
\hline$\cdot / \Delta \cdot 1$ & $\cdot \cdots$ & rq//FD & $s \psi / \Lambda \cdot 4$ & 1 & $\varepsilon F / \lambda \cdot F$ & مديريت استرس & קروه \\
\hline . MTF & $\cdot / \cdot \varphi \lambda$ & $F / \| F$ & 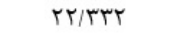 & 1 & אTr/Tr & حمايت بينفردى & \\
\hline.$/ 198$ &.$/ \cdot 14$ & $V / \cdot \varepsilon F$ & gD/FqT & 1 & GD/FqT & خودشكوفايى & \\
\hline \multirow{6}{*}{-} & \multirow{6}{*}{ - } & \multirow{6}{*}{ - } & १/४ . . & rq & $r \wedge I / r \cdot \Lambda$ & تغذيه & \multirow{6}{*}{ خطا } \\
\hline & & & V/Arq & rq & rTV/.r. & ورزش & \\
\hline & & & $\varphi / r \Delta \lambda$ & rq & IT\&/rqT & مسئوليتيذيرى & \\
\hline & & & TITT & rq & $s+/ 4 \lambda 1$ & مديريت استرس & \\
\hline & & & $\Delta / F T \Lambda$ & rq & $\mid \Delta V / F \cdot r$ & حمايت بينفردى & \\
\hline & & & 9/TVI & rq & TEN/AFG & خودشكوفايي & \\
\hline
\end{tabular}




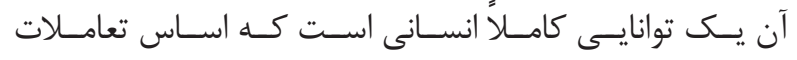

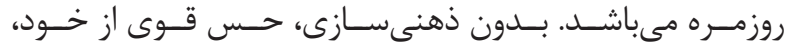

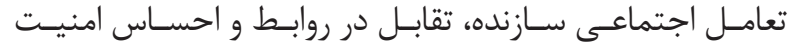

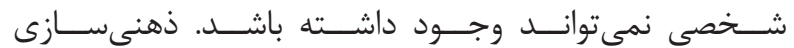

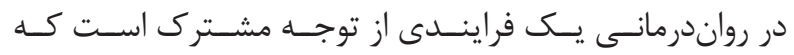

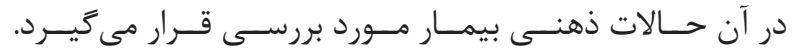

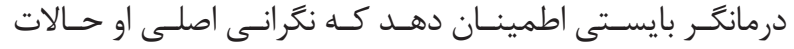

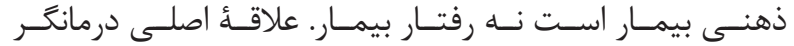

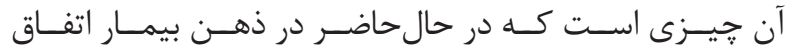

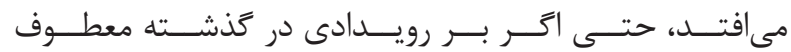

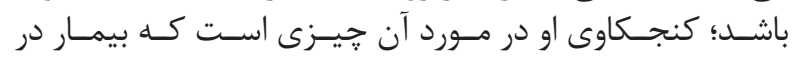

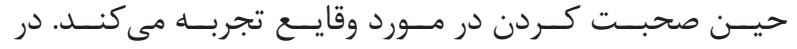

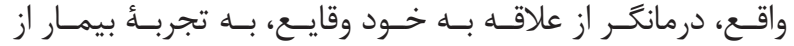

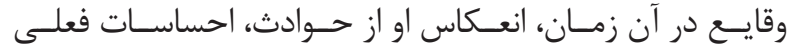

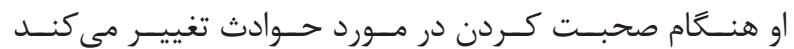

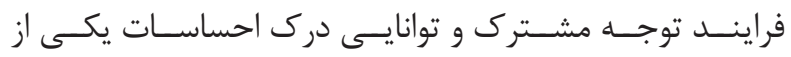

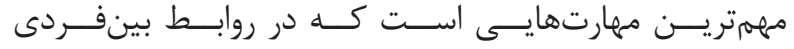

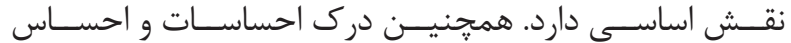

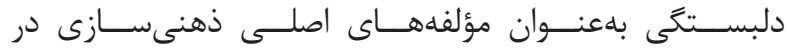

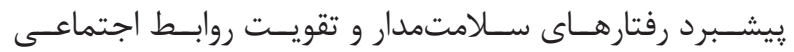

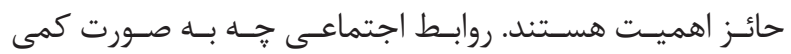

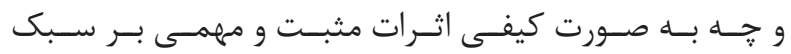

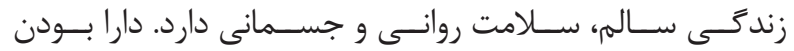

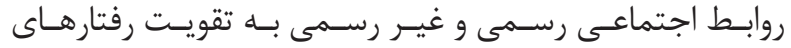

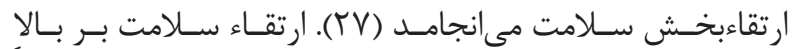

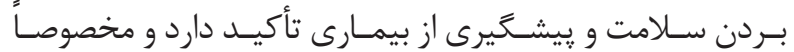

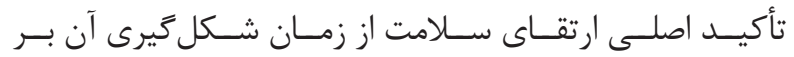

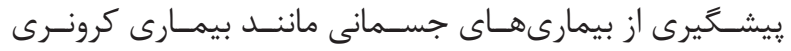

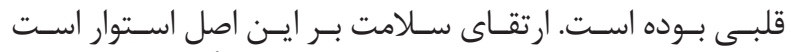

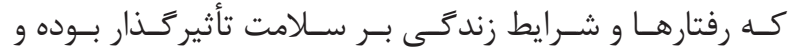

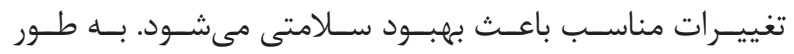

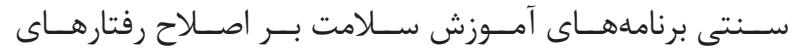

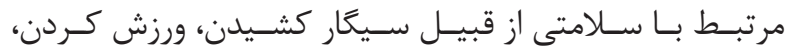

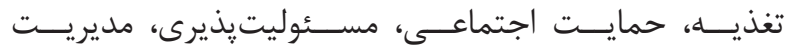

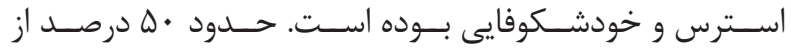

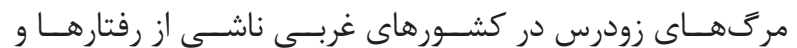

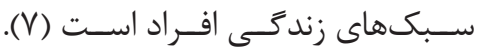

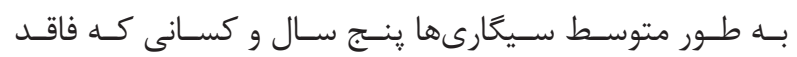

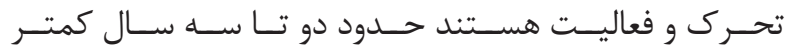

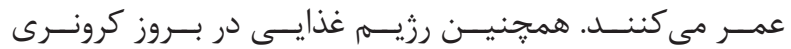

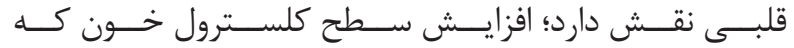

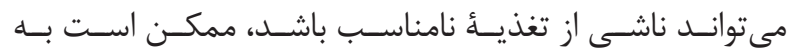

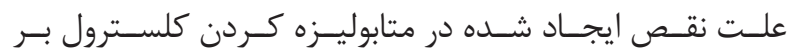

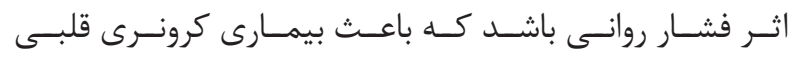

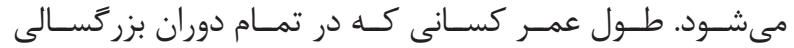

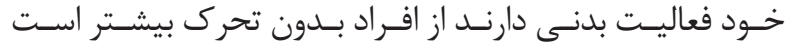

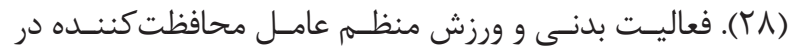

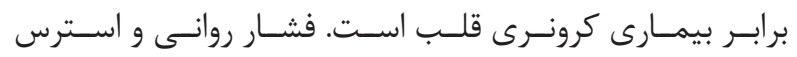

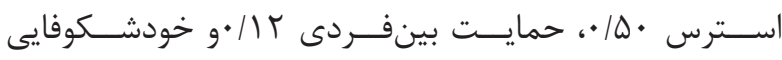

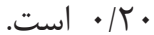

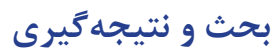

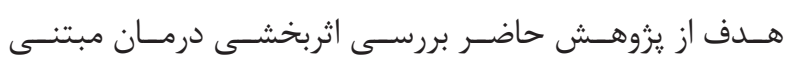

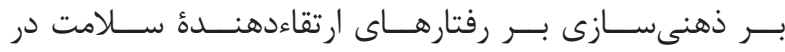

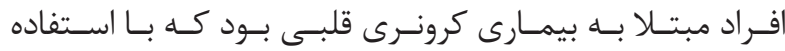

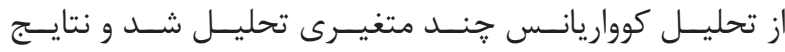

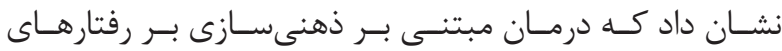

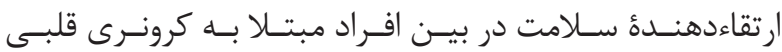

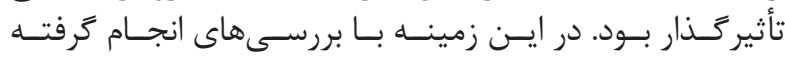

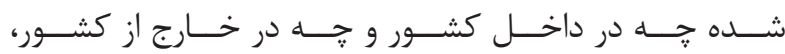

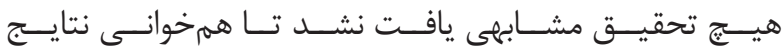

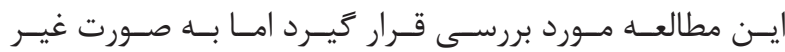

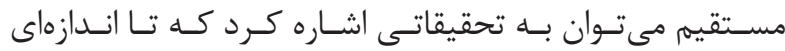

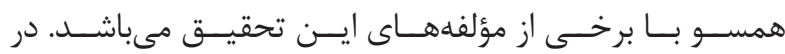

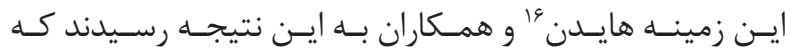

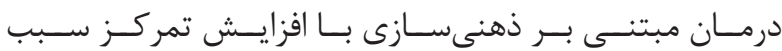

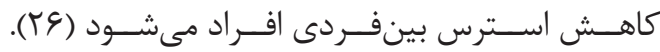

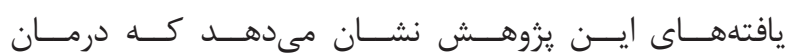

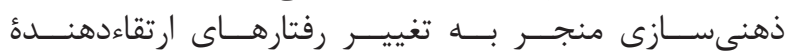

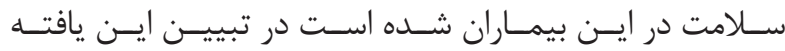

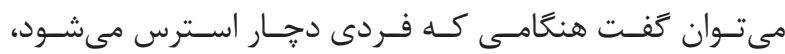

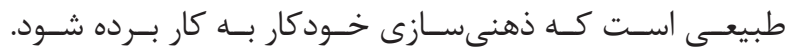

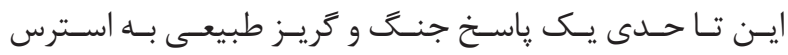

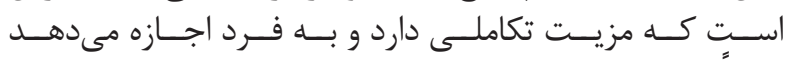

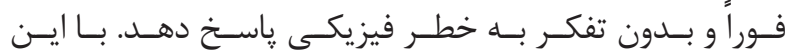

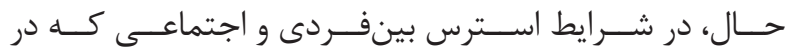

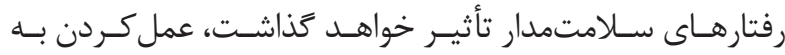

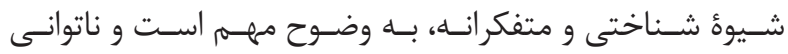

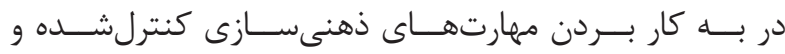

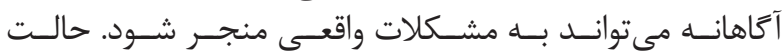

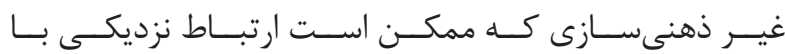

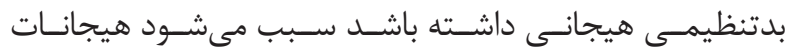

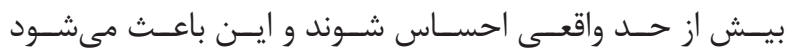

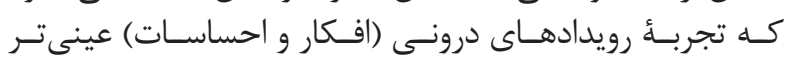

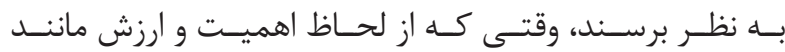

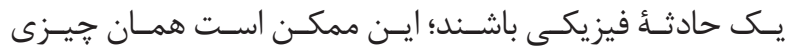

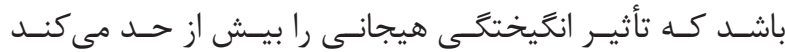

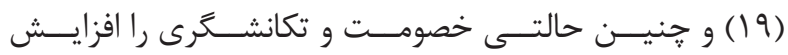

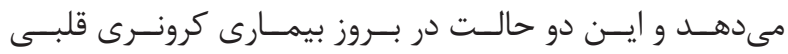

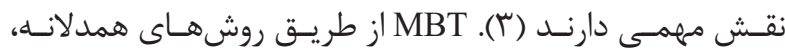

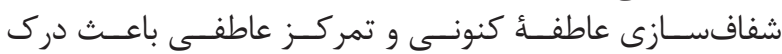

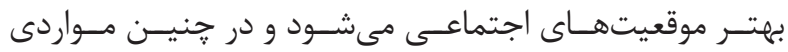

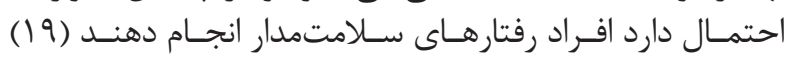

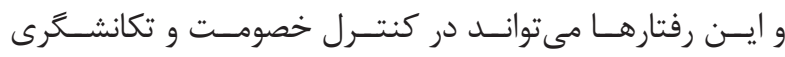

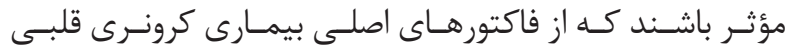

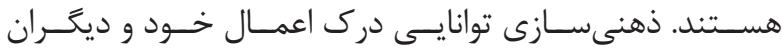

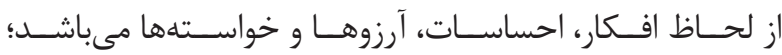




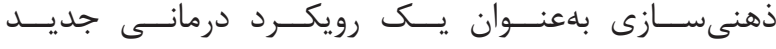

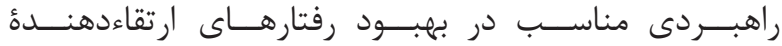

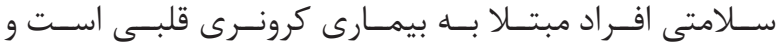

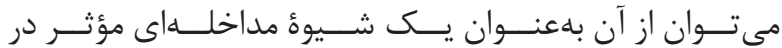

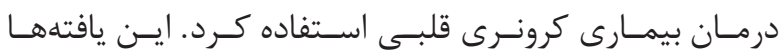

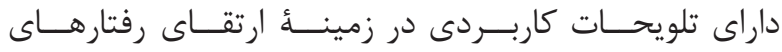

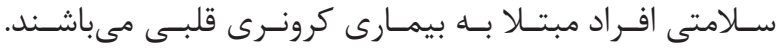

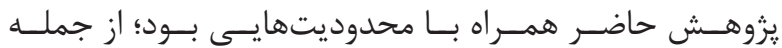

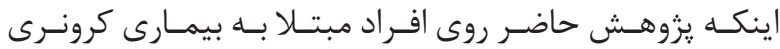

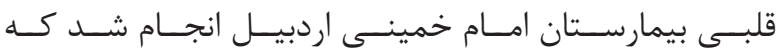

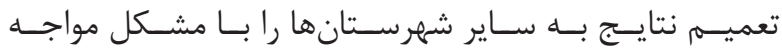

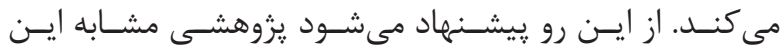

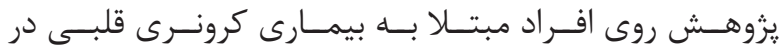

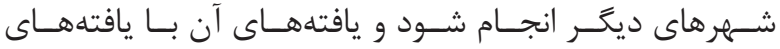

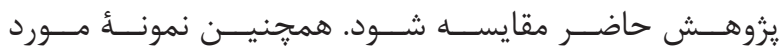

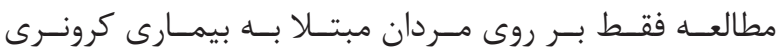

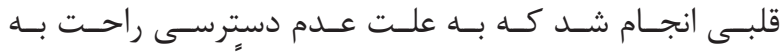

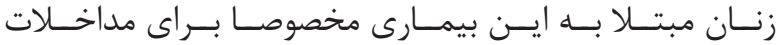

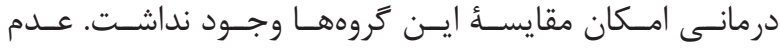

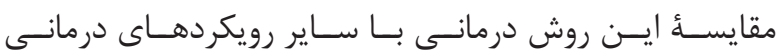

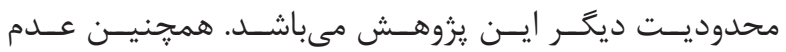

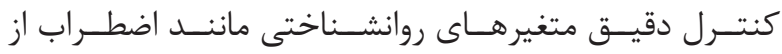

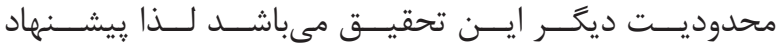

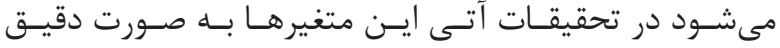

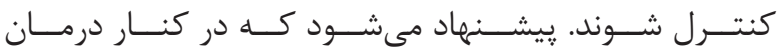

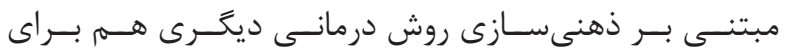

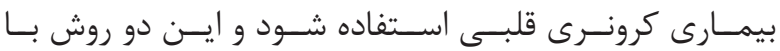

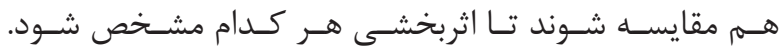
تشكر و قدردانى

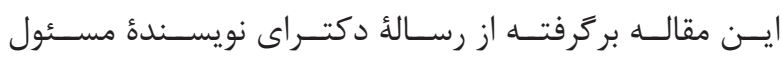

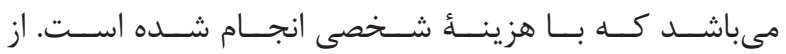

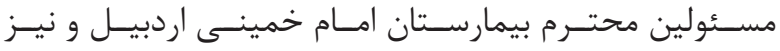

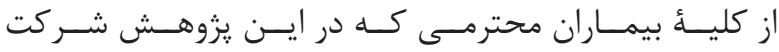

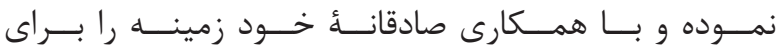

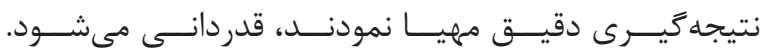

1. Musunuru K, Kathiresan S. Genetics of common, complex coronary artery disease. Cel. 2019; 177(1): 132-45.

2. Yousefi ZR, Ulamai R, Ulamai S. Providing a fuzzy expert system for modeling the diagnosis of coronary heart disease. Journal of Industrial Management Studies. 2019; 16(5): 27-52.

3. Yamout B, Issa Z, Herlopian A, El Bejjani M, Khalifa A, Ghadieh AS, et al. Predictors of quality of life among multiple sclerosis patients: a comprehensive analysis. Eur J Neurol. 2013; 20(5): 756-64.

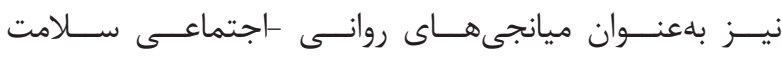

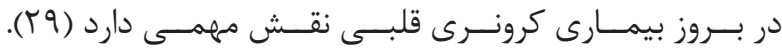

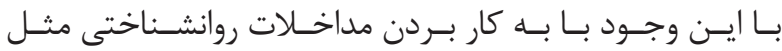

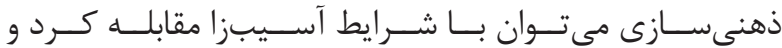

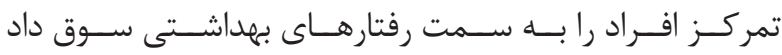

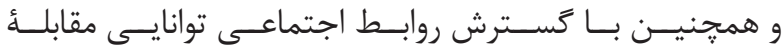

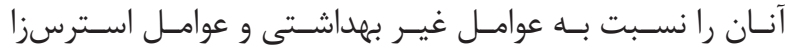

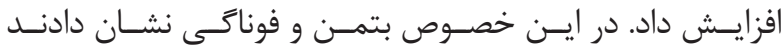

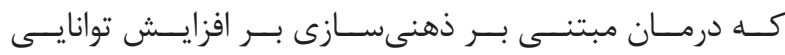

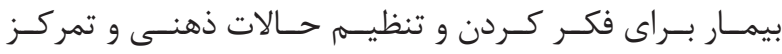

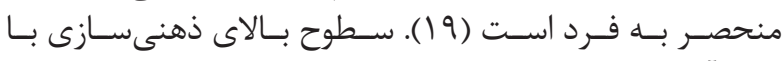

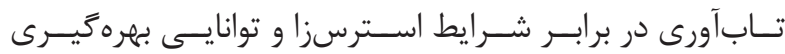

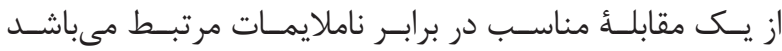

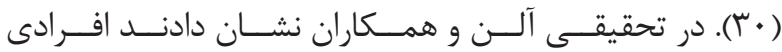

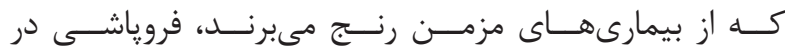

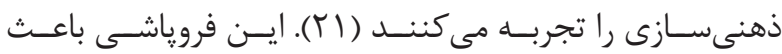

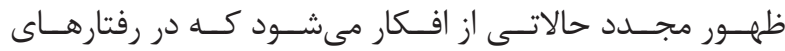

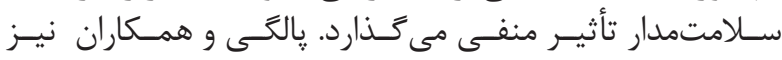

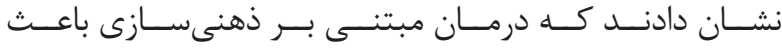

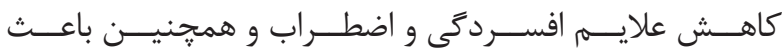

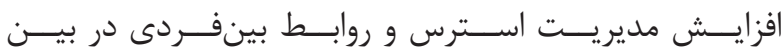

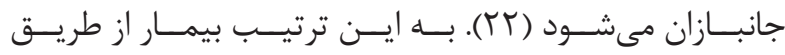

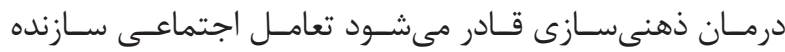

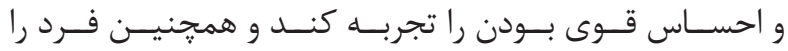

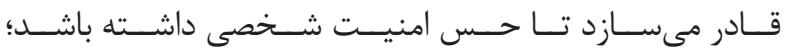

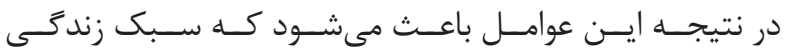

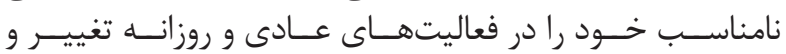

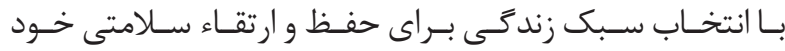

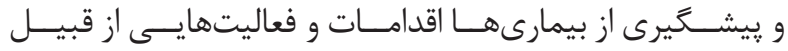

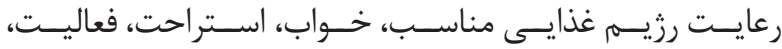

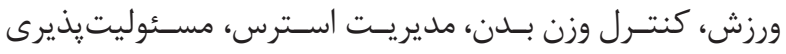

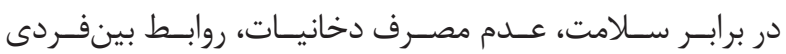

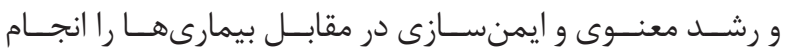

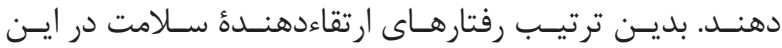

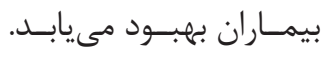

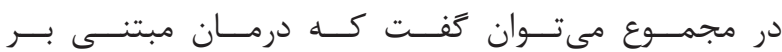

منابع

4. Khayam Nekouei Z, Yousefy A, Manshaee Q. The effect of cognitive-behavioral therapy on the improvement of cardiac patients' life quality. Iranian Journal of Medical Education. 2010; 10(2): 148-53.

5. Eshah NF. Lifestyle and health promoting behaviours in Jordanian subjects without prior history of coronary heart disease. Int J Nurs Pract. 2011; 17(1): 27-35.

6. Nejat K, Abedi H. Evaluation of health promotion activities in nurses. J Nov Appl Sci. 2015; 4(6): 715-20.

7. Michie S, Yardley L, West R, Patrick K, Greaves F. 


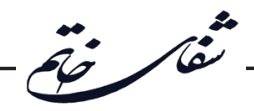

Developing and evaluating digital interventions to promote behavior change in health and health care: recommendations resulting from an international workshop. Journal of Medical Internet Research. 2017; 19(6): 23-36.

8. Amini Khooei N, Sheykhiani M, Fakouri Z. Coping skills with mental health of womens teachers. Woman and Society. 2011; 2(2): 103-27.

9. Edelman CL, Mandle, CL. Health Promotion throughout the Life Span. $6^{\text {th }}$ ed. USA: Mosby. 2006.

10. World Health Organization. http://www.who.int / topics/health promotion/ en. 2015.

11. Baheiraei A, Mirghafourvand M. Health promotion: from concepts to practice. Tehran: Noore- Danesh; 2011.

12. Myers RE. Promoting healthy behaviors: how do we get the message across? Int J Nurs Stud. 2010; 47(4): 500-12.

13. Mo PK, Winnie WSM. The influence of health promoting practices on the quality of life of community adults in Hong Kong. Social Indicators Research. 2010; 95(3): 503-17.

14. Mohamadi ZeidiA, Pakpor Haji Agha A, Mohammadi Zaidi B. Validity and reliability of the Persian version of health promoting lifestyle questionnaire. Mazandaran University of Medical Sciences.2011; 21(1): 103-13.

15. Gholizadeh M. Effectiveness of stress reduction education based on self-awareness on health status, negative emotions and symptoms of coronary heart disease. MSc Thesis, University of Tabriz. 2018.

16. Sochos A, Biskanaki F, Tassoulas E. Attachment style and interpersonal difficulties in immigrants with coronary heart disease. North American Journal of Psychology. 2006; 8(1): 145-62.

17. Huis emj, Veld E, Vingerhoets AJJM, Denollet J. Attachment style and self-esteem: The mediating role of Type D personality. Personality and Individual Differences. 2011; 50(7): 1099-103.

18. Bateman A, Fonagy P. Psychotherapy for borderline personality disorder: Mentalization- based treatment. Oxford, UK: Oxford University Press; 2004.

19. Bateman A, Fonagy P. Mentalization-based treatment for personality disorders. $1^{\text {th }}$ ed. United Kingdom: Oxford University Press; 2016.

20. Oliveira CD, Rahioui H, Smadja M, Gorsane MA, Louppe F. Mentalization based treatment and borderline personality disorder. L'Encéphale. 2017; 43(4): 340-45. 21. Bateman AW, Fonagy P Handbook of mentalizing in mental health practice. (pp. 419-444). Washington, DC: American Psychiatric Publishing. 2012; p. 419-444.

22. Palgi SH, Palgi Y, Ben-Ezra M, Shrira A. I will fear no evil, for I am with me: Mentalization-oriented intervention with PTSD patients. A case study. J Contemp Psychother. 2014; 44(3): 173-82.

23. Delavar A. Theoretical and practical research in the humanities and social sciences. $1^{\text {th }}$ ed. Tehran: Roshd Press. 2011.

24. Walker SN, Hill-Polerecky DM. Psychometric evaluation of Health Promoting Lifestyle Profile II. Unpublished manuscript, University of Nebraska Medical Center, College of Nursing, Lincoln. 1997.

25. Taymoori P, Moeini B, Lubans D, Bharami M. Development and psychometric testing of the adolescent healthy lifestyle questionnaire. J Edu Health Promot. 2012; 1(20): 1-7.

26. Hayden MC, Müllauer PK, Gaugeler R, Senft B, Andreas S. Improvements in mentalization predict improvements in interpersonal distress in patients with mental disorders. J Clin Psychol. 2018; 74: 2276-86.

27. Ball K, Jeffery RW, Abbott G, McNaughton SA, Crawford D. Is healthy behavior contagious: associations of social norms with physical activity and healthy eating? Int J Behav Nutr Phys Act. 2010; 7(86): 1-9.

28. Schwarzer R, Scholz U, Lippke S, Sniehotta FF, Ziegelmann JP. Self-regulatory processes in health behavior change. In Progress in Psychological Science Around the World.Proceedings of the 28th International Congress of Psychology. Routledge. 2019.

29. Abdolkarimy M, Zareipour M, Mahmoodi H, Dashti S, Faryabi R, Movahed E. Health promoting behaviors and their relationship with self-efficacy of health workers. IJN. 2017; 30(105): 68-79.

30. Bateman A, Fonagy P. Mentalization based treatment for borderline personality disorder. World Psychiatry. 2010; 9(1): 11-5. 